\title{
Chronic cardiac beriberi in a former prisoner of the Japanese
}

\author{
BY G. V. GILL* \\ Department of Tropical Medicine, Liverpool School of Tropical Medicine, \\ Pembroke Place, Liverpool L3 5QA
}

L. HENRY

Department of Pathology, University of Sheffield, Beech Hill Road, Shefftetu -

AND

H. A. REID

Department of Tropical Medicine, Liverpool School of Tropical Medicine, Pembroke Place, Liverpool $L_{3} 5 Q A$

(Received 2 June 1980 - Accepted 9 June 1980)

\begin{abstract}
1. A case is described of an Englishman who suffered severe 'wet beriberi' whilst a prisoner of war (POW) of the Japanese in World War II.

2. Following release he developed a congestive cardiomyopathy which increased in severity until his death 31 years after repatriation.

3. Autopsy findings were consistent with chronic cardiac damage due to beriberi.
\end{abstract}

Heart failure due to thiamine deficiency ('wet beriberi') is now rare, even in the tropics. Vitamin treatment is usually successful, but occasionally irreversible myocardial damage results. We report here a British patient who suffered from wet beriberi whilst a prisoner of war (POW) of the Japanese during World War II, and developed a congestive cardiomyopathy due to this which was diagnosed post mortem over 30 years later.

\section{Case report}

In early I976 a 60-year-old man was referred to hospital with moderately severe biventricular heart failure. He had been fit until imprisoned in the Far East during World War II. There he suffered from malaria, dysentery, peripheral neuropathy ('dry beriberi'), and severe and prolonged oedema due to wet beriberi. On repatriation in 1945 he was given vitamin therapy and he recovered. However, some 5 years later he began to experience episodes of oedema with breathlessness and occasional chest pain. He was found to be in atrial fibrillation and mild heart failure, and was treated subsequently with digoxin, and intermittent diuretics. His heart disease was presumed to be ischaemic in nature. In 1974 he had been assessed at the Liverpool School of Tropical Medicine where atrial fibrillation and slight cardiomegaly were found, but no signs of heart failure (he was taking diuretics at the time). He was also noted to have paraesthesia of the extremities and possible strongyloidiasis.

- Present address: Department of Clinical Biochemistry, Royal Victoria Infirmary, Newcastle upon Tyne, NEI 4LP.

0007-1 1 45/80/3538-0906 \$01.00 C I980 The Nutrition Society 
When referred in 1976 his main symptoms were of swelling and orthopnoea, and his physical signs included atrial fibrillation, oedema up to the thighs, cardiomegaly, basal pleural effusions and basal crepitations. He also had a left recurrent laryngeal nerve palsy. Blood pressure and pulse rate were normal and he had no murmurs or added heart sounds. Electrocardiogram (ECG) confirmed atrial fibrillation with no other specific features, and chest $\mathrm{X}$-ray showed cardiomegaly, pulmonary oedema, and small bilateral basal pleural effusions. He was treated vigorously with diuretics, and improved somewhat. In November 1976, however, he was admitted urgently with pneumonia and severe heart failure, and despite treatment he died the next day.

Autopsy confirmed the presence of pneumonia, and a pericardial effusion was also found. The heart weighed $650 \mathrm{~g}$ and both ventricles were dilated. The coronary arteries were grossly normal, and a small area of fibrosis at the tip of the left ventricle was noted. Histology of the myocardium (Plate I) revealed congestion and interstitial oedema, generalized interstitial fibrosis, and a variation in size of the myocardial fibres. The coronary arteries were histologically normal. No other significant gross or histological abnormalities were found in other systems. The features were thought to be those of a congestive cardiomyopathy with no evidence of coronary atheroma.

\section{Comment}

Though the histological features of beriberi cardiomyopathy are not specific, the abnormalities in this patient are similar to those found by other workers (Weiss, 1940; Alleman \& Stollerman, 1948; Schlessinger \& Benchimol, 195I). It thus seems probable that our patient suffered irreversible cardiac damage due to severe wet beriberi, and that this caused a symptomatic cardiomyopathy over the subsequent 3 I years. Atrial fibrillation has been described in cardiac beriberi, albeit rarely (Weiss \& Wilkins, 1937), and cases have previously been mistaken for ischaemic heart disease (Schlessinger \& Benchimol, I95I). It is probably of significance that our patient had persisting paraesthesia since his POW days, and also a recurrent laryngeal nerve palsy (nutritionally-induced recurrent laryngeal nerve paralysis has been described rarely in former Far East POW's by Walters et al. 197I).

Persisting cardiac beriberi, despite vitamin treatment, was described in two American ex-Far East POW's by Alleman \& Stollerman (1948), but these men died soon after the war. We have come across no other cases in British ex-POW's, but as diagnosis in this instance was largely by chance, it seems highly likely that other cases must exist. In the light of this, former Japanese POW's with heart failure should perhaps be reassessed and in the event of death an autopsy sought.

The authors would like to thank Drs D. R. Bell, J. J. Daly, J. McCarthy and H. H. Pilling for their help.

\section{REFERENCES}

Alleman, R. J. \& Stollerman, G. H. (1948). Ann. int. Med. 28, 949.

Schlessinger, P. \& Benchimol, A. B. (I951). Am. Heart J. 42, 801 .

Walters, J. H., Caplan, J. P. \& Hayward, E. W. (197I). A FEPOW Survey. Report to the DHSS from Queen Mary's Hospital, Roehampton, London: H.M. Stationery Office.

Weiss S. (1940). J. Am. med. Ass. rr5, 832.

Weiss, S. \& Wilkins, R. W. (1937). Ann. int. Med. II, ro4.

EXPLANATION OF PLATE

Section of myocardium showing hypertrophy of fibres with irregular nuclei, and interstitial fibrosis. 
British Fournal of Nutrition, Vol. 44 , No. 3

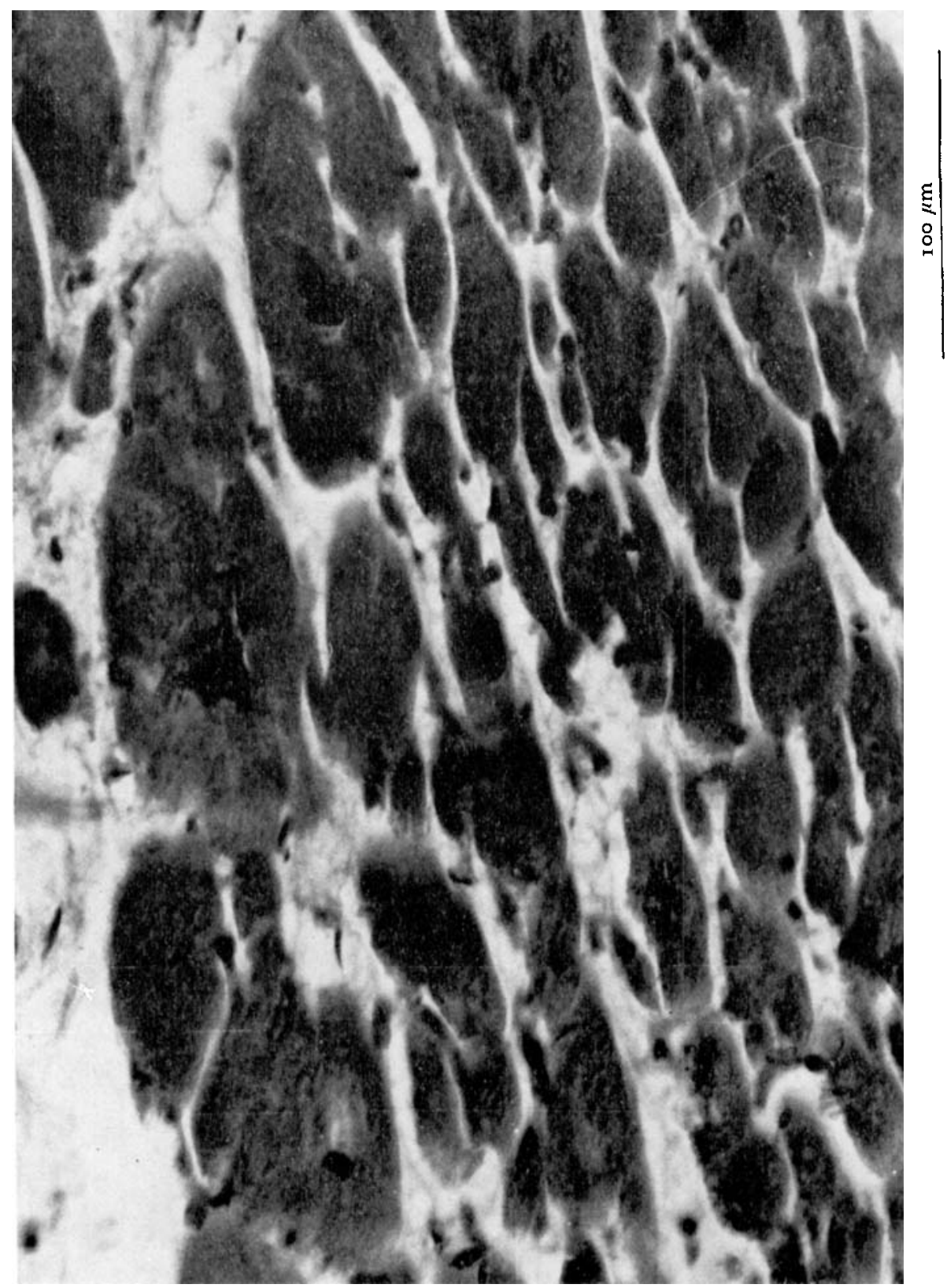

